\title{
An Integrated On-Board Battery Charger with a Nine- Phase PM Machine
}

\author{
N. Bodo, E. Levi, I. Subotic, M. Jones \\ Faculty of Engineering and Technology \\ Liverpool John Moores University \\ Liverpool, U.K.
}

\author{
J. Espina, L. Emprigham, M. Johnson \\ Power Electronics, Machines and Control Group \\ University of Nottingham \\ Nottingham, U.K.
}

\begin{abstract}
A fully integrated on-board battery charger for electrical vehicles (EVs) has been developed recently using a nine-phase machine. All the components used for propulsion are employed in the charging process, no additional components are required, and there is no need for hardware reconfiguration between charging and propulsion modes of operation. The proposed solution can be connected directly to single-phase or three-phase grid to perform charging, so that the expensive offboard charger infrastructure is not needed. The only requirement is to use a nine-phase machine in combination with a nine-phase inverter in the powertrain of the EV. This however inevitably brings in further advantages in the propulsion mode, such as increased fault tolerance and the current subdivision into more phases. The benefits of the topology, originally developed for an induction machine, make it interesting for further investigation. Therefore, the performance of the charger is examined here using a permanent magnet synchronous machine (PMSM). The results show that the charger topology is applicable to other types of synchronous machines and is, even more importantly, independent of the angular spatial shift between the individual three-phase windings of the nine-phase machine's stator. The results are comparable with those obtained using an induction machine and confirm the viability of the solution in conjunction with the PMSM as a propulsion motor.
\end{abstract}

Keywords-Battery chargers, electric vehicles, integrated onboard charger, multiphase machines

\section{INTRODUCTION}

Induction and permanent magnet machines have been identified as the ones utilized in the vast majority of cases in EVs' powertrains [1]. Typically, three-phase version is used. However, employing multiphase machines in the powertrain of the vehicle is beneficial in propulsion mode, since multiphase machines inherently have better fault tolerance and also split the current supplied to the machine into more phases [2]. This opens up the possibility of simple realization of the limp-home mode with a slight degradation of the performance in the case of any of the machine's windings or inverter legs becoming open-circuited. Indeed, in the case of a nine-phase machine, the simplest post-fault operating strategy is to take out a complete three-phase windings where the open-circuit fault has taken place. Current splitting into more phases, on the other hand, enables utilization of semiconductors of lower current/power rating.

If a nine-phase machine is employed for propulsion in an $\mathrm{EV}$ in conjunction with a nine-phase inverter, it becomes possible to realise in a simple manner fully integrated on- board charging of the battery. This applies to both slow singlephase [3] and fast three-phase [4] charging. The original proposals and performance characterisations have been performed in [3, 4] using a nine-phase induction machine. This paper confirms the viability of this battery charging topology when the propulsion system incorporates a ninephase PMSM. Hence the paper confirms the validity of the charger structure for all the ac machine types that operate using the principle of the Tesla's rotating field.

The topology of the integrated charger, as developed in [3] and [4] for single-phase and three-phase charging, is characterised with numerous beneficial properties. The charger is completely integrated in the propulsion subsystem, and neither additional hardware nor hardware reconfiguration is required. Neither single-phase nor three-phase charging modes create resultant magnetic field in the air-gap of the machine and therefore there are no losses in the rotor. Even more importantly, there is no electromagnetic torque production while charging. The currents flowing into the grid are fully controllable by the nine-phase inverter and therefore unity power factor operation at the grid side and the possibility of bidirectional power flow - i.e. charging and vehicle-to-grid (V2G) power injection - are simple to realize.

Many alternative integrated solutions exist for single-phase [5] or three-phase [6-8] charging. Existing solutions for integrated three-phase charging, with three-phase machines, inevitably involve torque production (unless extra components are added). Hence, use of mechanical brake is recommended [9]. An interesting solution is the one of [10], which uses a three-phase stator winding configuration in propulsion mode and an equivalent of symmetrical six-phase configuration in charging mode. Since in propulsion each phase is supplied from an $\mathrm{H}$-bridge inverter, there is no current splitting into more than three phases; also, fault tolerant operation is much more restricted than with a nine-phase system.

PMSMs have in propulsion mode higher efficiency, torque and energy density, when compared to induction machines, and therefore take a substantial role in the EV drivetrain market [11]. The extension of the charger functionality from induction machines to PMSMs indicates that the charger can be operated using any nine-phase machine, provided that its operation is based on the principal of rotating field creation by the stator. The PMSM used here has been obtained by rewinding a 36-slot stator of a three-phase six-pole PM machine. Therefore, the machine has an irregular space-shift between its three three-phase windings. While the symmetrical 


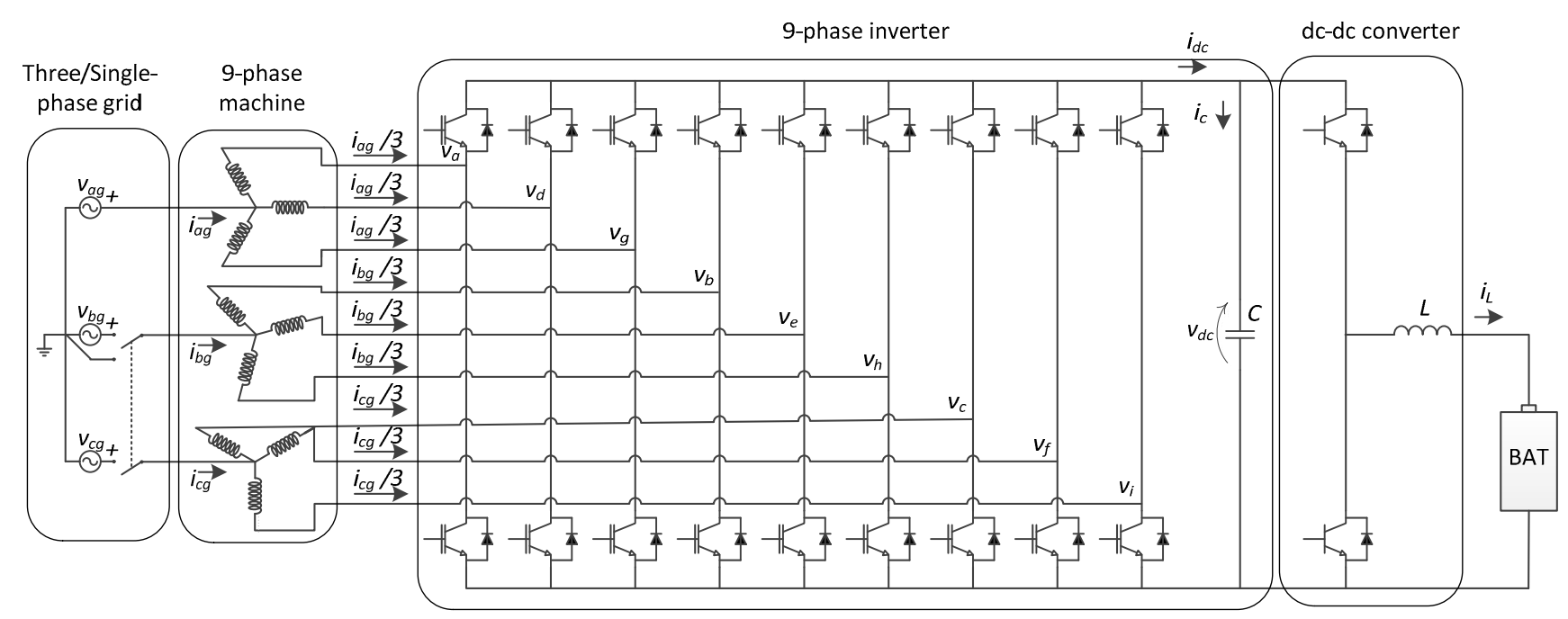

Fig. 1. Topology of the nine-phase integrated on-board battery charger for three-phase and single-phase grid connection in the charging mode.

nine-phase machines are characterised with $40^{\circ}$ shift between three-phase sets and the asymmetrical nine-phase machines have $20^{\circ}$, the machine used here has $15^{\circ}$. The successful implementation of the charging scheme proves the independence of this variable. Therefore, it can be postulated that the system would work equally well with a triple threephase machine, where the three-phase windings are actually aligned in space. This has been verified for the case of three separate machines in [12]. Such a machine is believed to be closer to a standard three-phase machine and hence more likely to be used in real-world applications than the nine-phase machines with spatially shifted windings.

\section{SYSTEM DESCRIPTION AND CONTROL}

The integrated charger/propulsion system is shown in Fig. 1, [4]. Without the electrical grid connected to the three separate neutral points of the machine on the left, the system represents a classical propulsion setup for EVs. It consists of a battery with internal battery management system; a dc/dc converter to adjust the battery voltage to the required dc-bus voltage; an inverter connected to the dc-bus; and a machine. The system can be driven with classical field oriented control, by using the appropriate decoupling and rotational transformations $[2,4]$. The difference with respect to a threephase topology is that the inverter and the machine are ninephase ones, with three isolated neutral points, which is convenient to connect to the electrical grid for charging. For charging, the inverter can be controlled so that the currents through each winding of any individual three-phase set are the same and in phase with the grid voltage connected to that particular neutral point. As a consequence of the spatial disposition of the windings belonging to an individual threephase set, the created flux will cancel in the air-gap and neither torque nor rotor losses will be produced. For threephase charging all three neutral points are used, while singlephase charging utilizes two out of the three neutral points.

The control scheme is depicted in Fig. 2. The currents of the nine phases are sensed and transformed using three threephase decoupling transformations. The zero-sequence currents represent the individual sums of the currents flowing through the same machine's three-phase winding or, in other words, the grid currents. They are forwarded to the main current controllers (MCCs) that provide reference voltage signals to achieve the desired value of the grid phase currents. The values of the grid phase currents are actually influenced by the voltage drop on the machine phase impedances. Although the current controllers can output the sum of the grid voltage and reference voltage drop on the machine phases, to avoid large initial currents when the controllers have zero output, the actual measurements of the grid voltages are added to the output of the controllers ( $v_{a g}, v_{b g}$ and $v_{c g}$ in three-phase, $+v_{a g} / 2$ and $-v_{a g} / 2$ in single-phase charging, $\left.[3,4]\right)$.

The $\alpha-\beta$ components after the decoupling transformations represent the imbalances between the three currents of the same three-phase winding set, and are therefore controlled to zero by the balancing current controllers (BCCs). The voltage references from both controller sets (MCCs and BCCs), obtained in this way, are then passed through three inverse decoupling transformations and applied to a PWM output block that generates the gating signals for the inverter. In the case of single-phase charging, only two decoupling transformations are used that relate to the three-phase sets connected to the grid. Since three phases are in both cases paralleled, interleaving can be used, as discussed later.

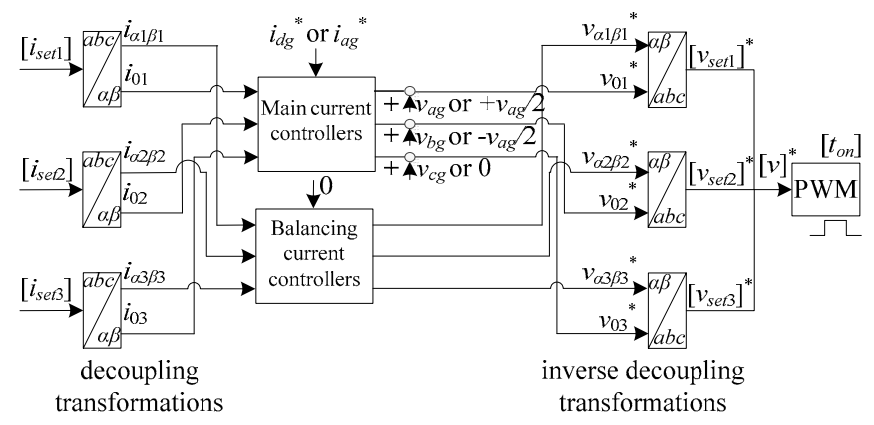

Fig. 2. Control of the converter for three-phase and single-phase grid connection $\left(i_{d g}{ }^{*}\right.$ is the reference for the $d$-axis component of the three-phase grid current; $i_{a g}{ }^{*}$ is the grid current reference in single-phase connection). 

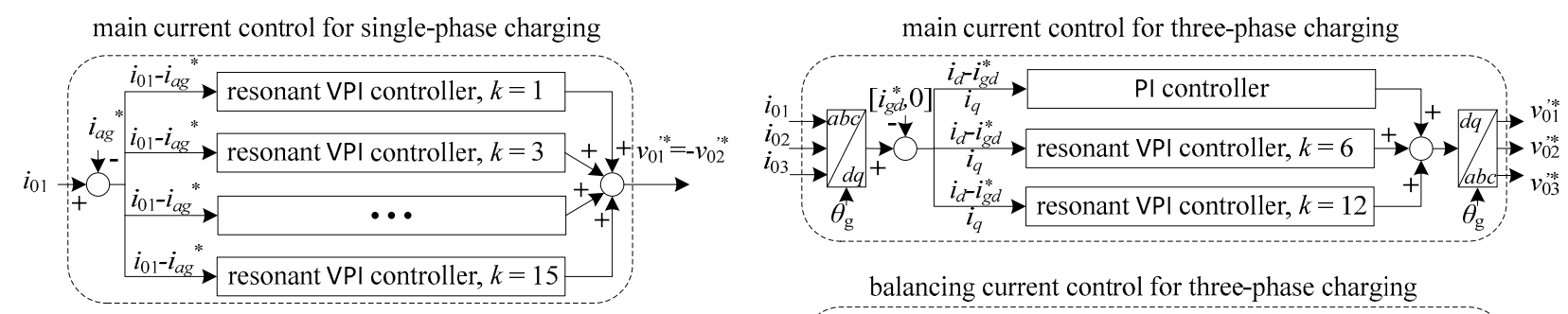

balancing current control for single-phase charging
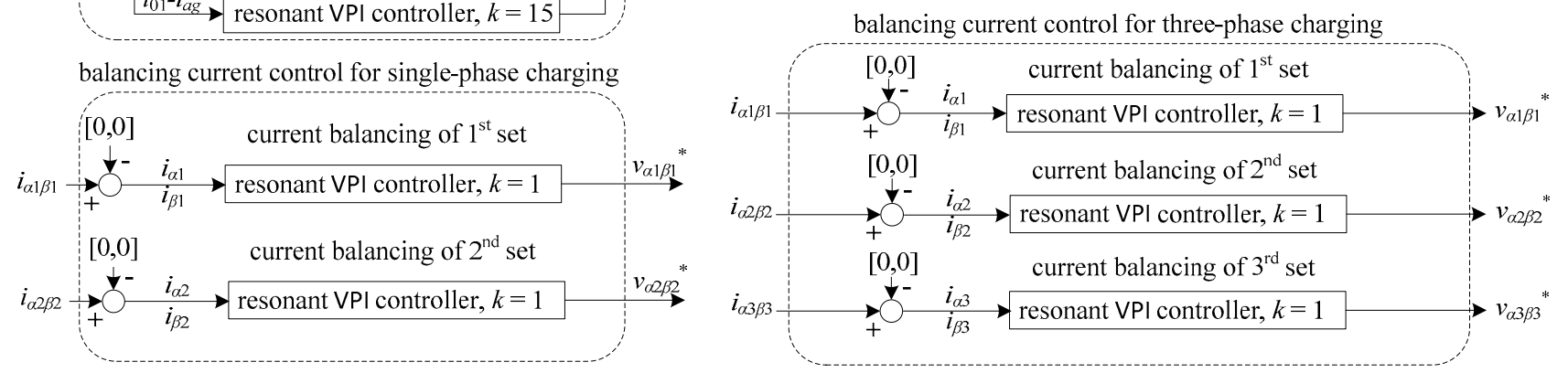

Fig. 3. Current controllers of Fig. 2 for single-phase (left) and three-phase (right) grid connection.

The current controllers for the two charging modes are depicted in Fig. 3. The controllers used for single-phase charging are shown on the left side. The controllers used are resonant vector proportional-integral (VPI) controllers [3]. They are placed in the stationary reference frame and are adjusted to mitigate the harmonic $k$. Therefore the MCCs control the fundamental to meet the desired grid current; additionally, they also perform the second task, to zero all the odd harmonics up to the $15^{\text {th }}$, while the BCCs control only the fundamental in the two active three-phase sets to zero.

In the case of the three-phase charging, the MCCs are placed in the grid voltage oriented reference frame, using the rotational transformation in conjunction with the grid voltage position obtained from a phase locked loop (not shown in the figure). In this way the PI controller sees the fundamental grid current as a dc component and controls it to the desired grid current $d$ component, while the $q$ component is controlled to zero.

The resonant VPI controllers are also in the voltage oriented reference frame and therefore control the $1 \pm k^{\text {th }}$ (i.e $5^{\text {th }}, 7^{\text {th }}, 11^{\text {th }}$ and $13^{\text {th }}$ ) harmonics to zero. The balancing current controllers are similar to the ones in the single-phase charging case. They are positioned in the stationary reference frame and control the fundamental to zero, only this time in all three sets of three-phase windings.

\section{EXPERIMENTAL SETUP}

The results presented here are obtained using a different experimental setup than the one utilized in [3, 4]. As shown in Fig. 4, the single-phase or three-phase grid is connected to the nine-phase PMSM. Further details regarding the setup and construction of the machine can be found in the Appendix. The machine is connected to a converter system encompassing the nine-phase inverter and the $\mathrm{dc} / \mathrm{dc}$ converter in the common enclosure. The IGBT converter was custom made for the purposes of the demonstration of the viability of the integrated charger concept. The nine-phase machine is connected to the nine-phase inverter, which connects to the high-voltage side of the $\mathrm{dc} / \mathrm{dc}$ converter; the low voltage side of the bidirectional $\mathrm{dc} / \mathrm{dc}$ converter is connected to the battery stack through an $L C L$ filter (shown just as $L$ in Fig. 1 for simplicity).

The switching frequency of the inverter and $\mathrm{dc} / \mathrm{dc}$ converter was set to $10 \mathrm{kHz}$ with asymmetrical PWM and a $1.5 \mu \mathrm{s}$ dead time is adopted in all of the inverter legs and in the $\mathrm{dc} / \mathrm{dc}$ converter. The switches used for the nine-phase converter are Semikron SK15GD12T4ET and for the dc/dc converter are Semikron SK100GH12T4T. The dc-bus capacitance contains a combination of electrolytic and ceramic capacitors and amounts to an equivalent of $1162 \mu \mathrm{F}$ on the high-voltage dc side. Experiments are performed with and without interleaving of the inverter legs.

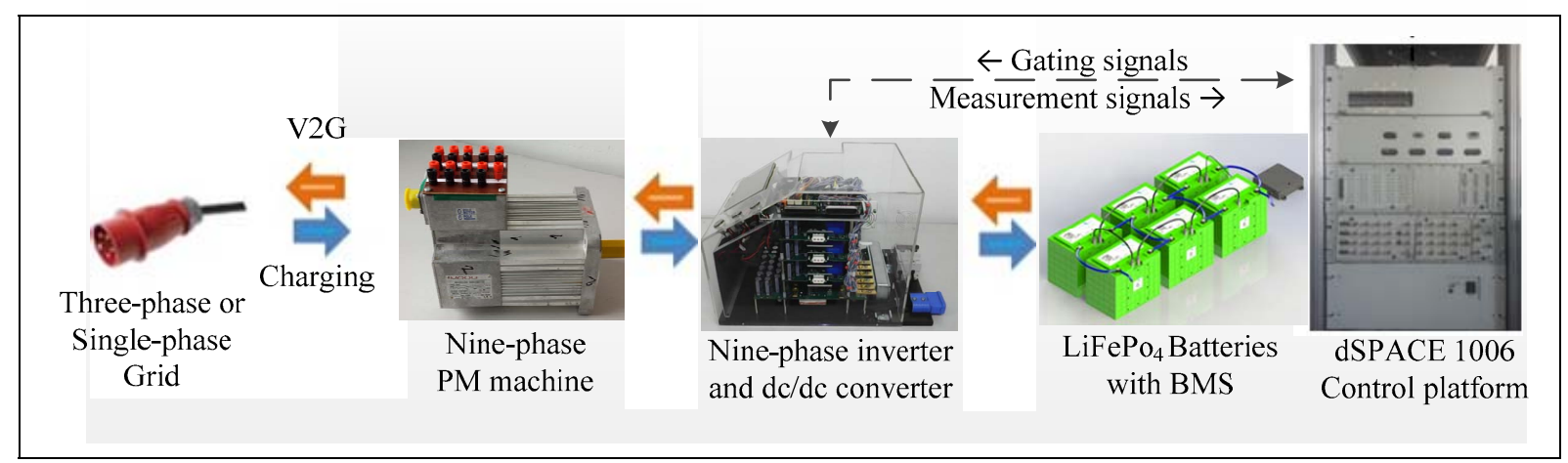

Fig. 4. Experimental setup. 
The rating of the nine-phase inverter is approximately $30 \mathrm{kVA}$ and the rating of the $\mathrm{dc} / \mathrm{dc}$ converter is $7.5 \mathrm{~kW}$ with a single half-bridge. The number of half-bridges can be increased and interleaving could be applied between them. At the low voltage side, the role of the $L C L$ filter is to protect the battery stack from the harmful current ripple created by the $\mathrm{dc} / \mathrm{dc}$ converter. It comprises a larger inductance of $660 \mu \mathrm{H}$, depicted in Fig. 1, a capacitance of $220 \mu \mathrm{F}$ and a smaller inductance of $220 \mu \mathrm{H}$. The $L C L$ filter provides the filtering effect similar to a much larger pure $L$ filter, by taking a fraction of its weight and volume.

Finally, the battery stack comprises 10 units of $12 \mathrm{~V}$ $\mathrm{LiFePO}_{4}$ battery packs connected in series, with an independent battery management system capable of balancing the voltage and state-of-charge among the battery packs and battery cells within them. The stack provides a no-load voltage of $136 \mathrm{~V}$ with $40 \mathrm{Ah}$ capacity.

The value of the dc-bus voltage was set to $720 \mathrm{~V}$ for threephase charging/V2G and $450 \mathrm{~V}$ for single phase charging/V2G modes. It is to be noted that lowering of the dc-voltage can improve the overall efficiency of the topology because it makes the inverter work at maximal modulation indices, thus minimizing losses and current ripple towards the grid. However, optimizations of this type are out of the scope of the work presented here.

The setup does not need any hardware reconfiguration to switch between propulsion, single-phase and three-phase charging modes, except connection and disconnection of the grid power supply according to the desired mode of operation. It is also capable of performing limp-home (post-fault) operation by disabling the faulted three-phase set in propulsion mode. The whole system can be operated from a TMS320F28335 controller or by means of a dSPACE1006 control platform. The results presented in this paper are obtained by using the latter. As the PWM used is asymmetrical, the control loops are executed at $20 \mathrm{kHz}$ and include the control structures detailed in the previous section.

\section{EXPERIMENTAL RESULTS}

\section{A. Single-Phase Charging Mode}

Experimental results for the topology using a nine-phase induction machine have been reported in [3] for single-phase charging mode of operation. The results in this section are obtained by using a PMSM, as well as a lower dc-bus voltage than in [3].

The waveforms of the grid voltage, grid current, machine phase current and battery charging current are depicted in Fig. 5 and Fig. 6 for operation with and without interleaving. The FFTs of the grid and machine phase current are also included in Fig. 5 and Fig. 6. The waveforms for the V2G mode are given in Fig. 7 for the cases with and without interleaving. The FFTs are not shown for the V2G mode because of their similarity with the ones obtained for charging mode of operation.

Without application of the interleaving all the spectral components (low and high order harmonics) of the machine phase currents are the same because they are controlled to the same values and employ the same carrier signals. Therefore they get summed to form the grid current. The resulting grid current will inevitably have the same spectral content, except that harmonics will be three times larger than in the machine phase currents. Even without interleaving the grid current distortion is very low and at an acceptable level.
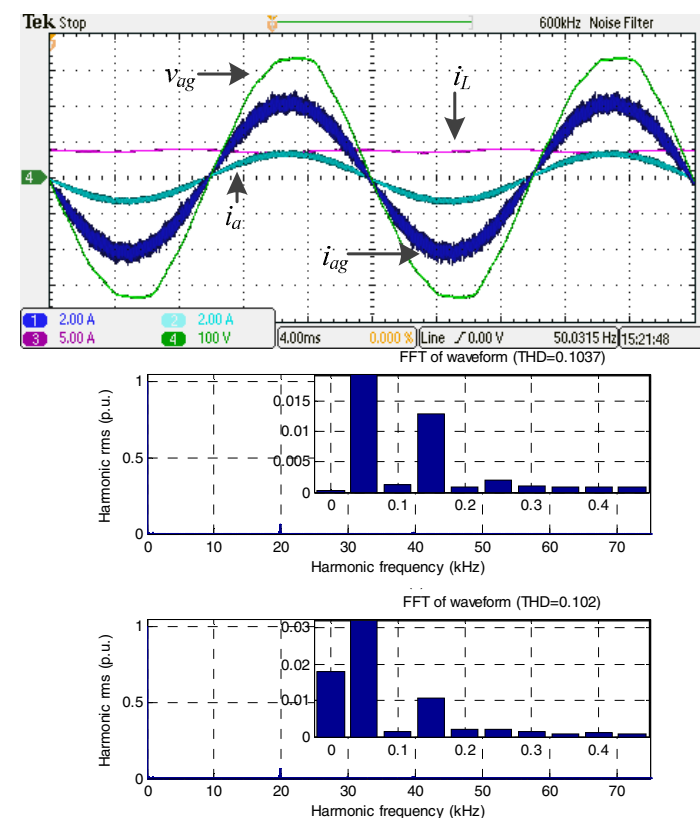

Fig. 5. PM machine, single-phase charging mode without interleaving (CH1 grid phase current $i_{a g}, \mathrm{CH} 2$ - machine phase current $i_{a}, \mathrm{CH} 3$ - battery charging current $i_{L}, \mathrm{CH} 4$ - grid phase voltage $v_{a g}$; from top to bottom: waveforms, grid current harmonics, and machine's phase current spectrum).
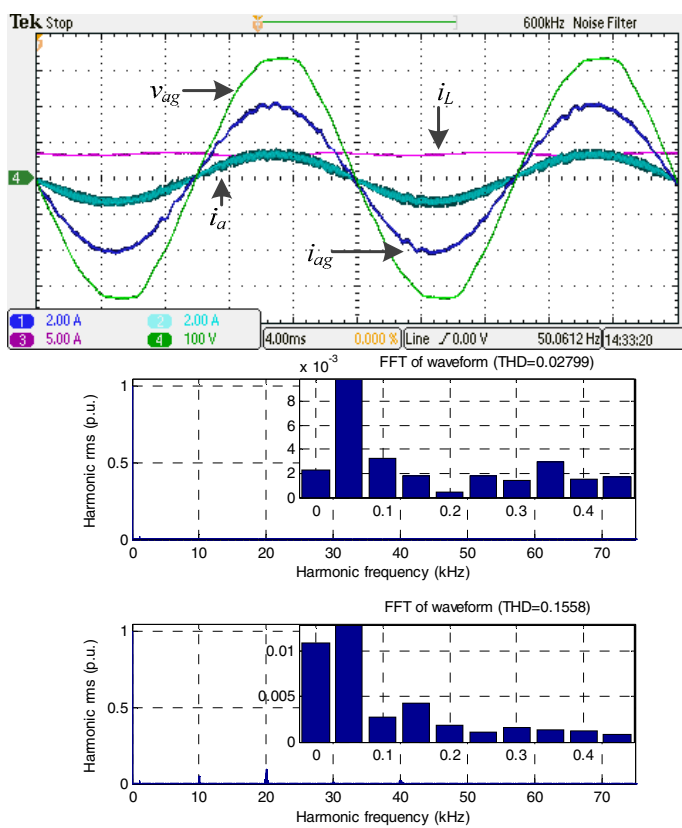

Fig. 6. PM machine, single-phase charging mode with interleaving (CH1 grid phase current $i_{a g}, \mathrm{CH} 2$ - machine phase current $i_{a}, \mathrm{CH} 3$ - battery charging current $i_{L}, \mathrm{CH} 4$ - grid phase voltage $v_{a g}$; from top to bottom: waveforms, grid current harmonics, and machine's phase current spectrum). 


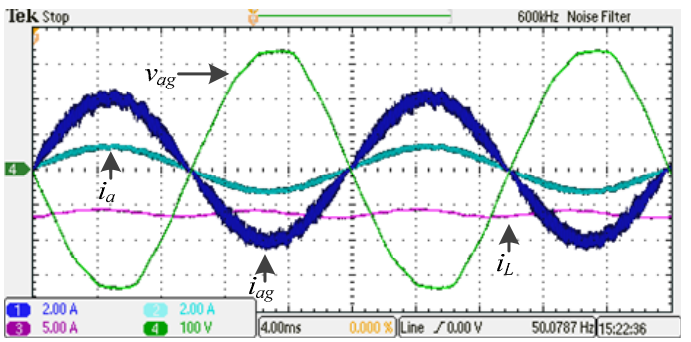

a)

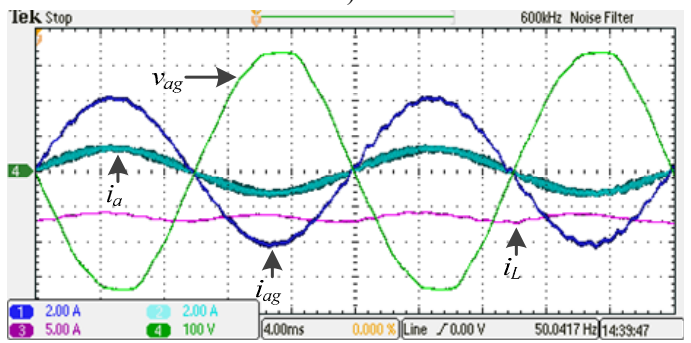

b)

Fig. 7. PM machine, single-phase V2G mode: a) without interleaving, (b) with interleaving $\left(\mathrm{CH} 1\right.$ - grid phase current $i_{a g}, \mathrm{CH} 2$ - machine phase current $i_{a}, \mathrm{CH} 3$ - battery charging current $i_{L}, \mathrm{CH} 4$ - grid phase voltage $v_{a g}$ ).

Once interleaving is applied the grid phase current has a substantially reduced high frequency ripple since the switching harmonics cancel out among the three phases connected to the same neutral point. However, inevitably, a portion of the machine phase current ripple will close its path by circulating through the three machine phases, causing the increase in the machine phase current ripple compared to the case without interleaving and also incurring additional losses. In Fig. 6 this is manifested in a substantial decrease of the grid current distortion (to less than a third) and a lesser increase (of about $50 \%$ ) in the machine's phase current distortion. This is also evident for $\mathrm{V} 2 \mathrm{G}$ mode in Fig. 7. The current ripple is influenced by the correlation of the voltage ripple produced by the three inverter legs of the same neutral. The inductance opposing the current ripple will change with interleaving since the machine phases share stator slots [13].

The figures depicting single-phase charging also demonstrate a reasonably ripple-free battery charging current and a dc-bus voltage controlled to around $450 \mathrm{~V}$. The second harmonic, usually present in single-phase charging application, is almost removed by the $L C L$ filter. This harmonic is caused by the power variation between the zero crossing instant and the instant the grid phase voltage and current reach their maximum. Unity power factor operation is evidenced by the fact that the grid phase voltage and current are in phase in both charging and V2G modes of operation.

\section{B. Three-Phase Charging Mode}

The results for the three-phase charging and $\mathrm{V} 2 \mathrm{G}$ are shown in Fig. 8, Fig. 9 and Fig. 10. The figures contain the waveforms obtained with and without interleaving, with the charging mode also presenting harmonic content of the grid and machine phase currents. The conclusions remain similar to those arrived at for the single-phase charging. The obtainable power range is now three times wider than with the singlephase charging. The power flow is constant within a fundamental period and therefore the battery charging current does not contain the second harmonic any more. The grid phase current has a higher ripple without interleaving, compared to the same current in single-phase charging, because of non-cancellation of the harmonic at $10 \mathrm{kHz}$ and only one half of the impedance opposing the current flow, compared to the single-phase charging mode.

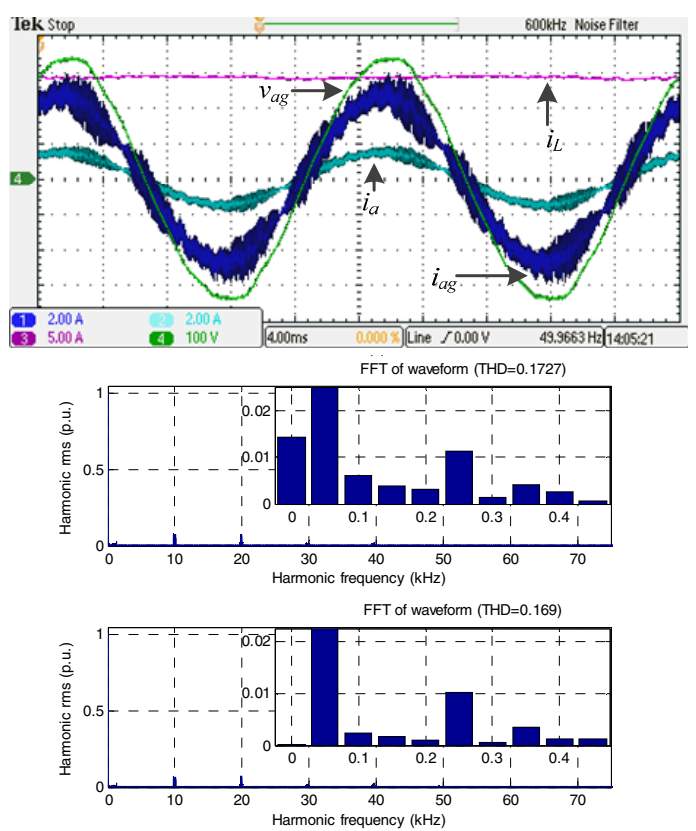

Fig. 8. PM machine, three-phase charging mode without interleaving $(\mathrm{CH} 1$ grid phase current $i_{a g}, \mathrm{CH} 2$ - machine phase current $i_{a}, \mathrm{CH} 3$ - battery charging current $i_{L}, \mathrm{CH} 4$ - grid phase voltage $v_{a g}$; from top to bottom: waveforms, grid current harmonics, and machine's phase current spectrum).
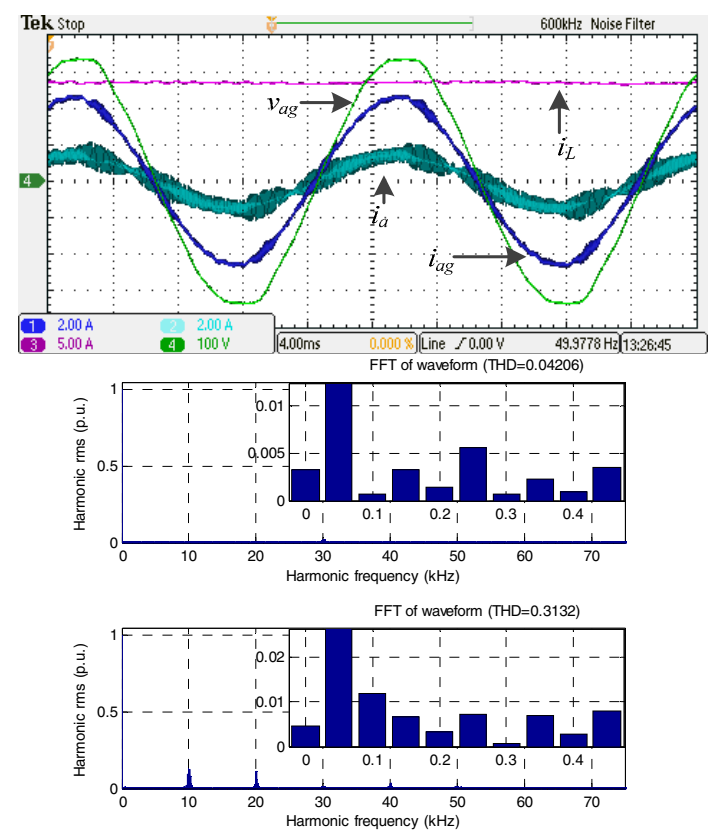

Fig. 9. PM machine, three-phase charging mode with interleaving (CH1 - grid phase current $i_{a g}, \mathrm{CH} 2$ - machine phase current $i_{a}, \mathrm{CH} 3$ - battery charging current $i_{L}, \mathrm{CH} 4$ - grid phase voltage $v_{a g}$; from top to bottom: waveforms, grid current harmonics, and machine's phase current spectrum). 


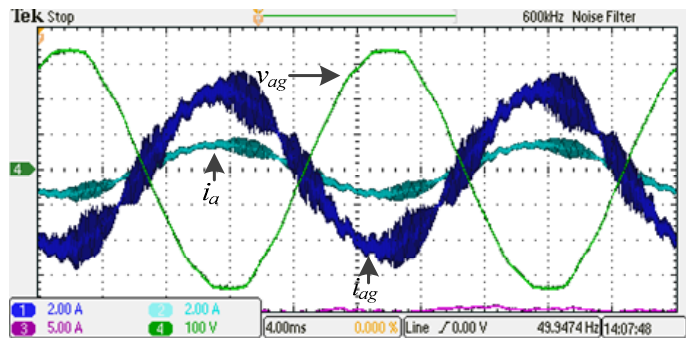

a)

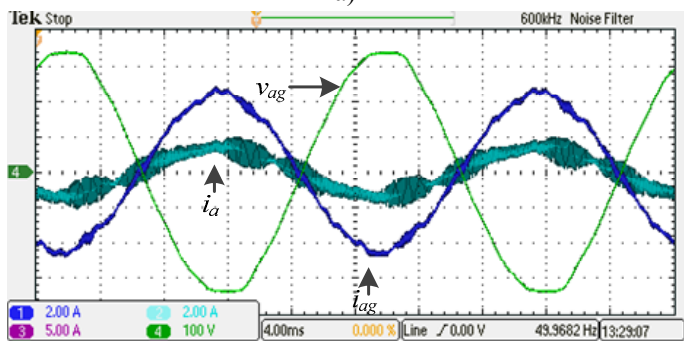

b)

Fig. 10. PM machine, three-phase V2G mode: a) without interleaving, (b) with interleaving $\left(\mathrm{CH} 1\right.$ - grid phase current $i_{a g}, \mathrm{CH} 2$ - machine phase current $i_{a}, \mathrm{CH} 3$ - battery charging current $i_{L}, \mathrm{CH} 4$ - grid phase voltage $v_{a g}$ ).

\section{CONCLUSIONS}

The paper verifies the functionality of the nine-phase integrated on-board charger/propulsion system for EVs using a PMSM. The performance is comparable with the previously reported ones using a nine-phase induction machine. The irregular winding distribution of the used PMSM proves that the topology can operate with any phase shift between the individual three-phase winding sets, ranging from symmetrical $\left(40^{\circ}\right.$ displacement $)$ to triple three-phase $\left(0^{\circ}\right.$ displacement $)$. Further, the different type of the machine used here confirms the viability of the solution for any rotor construction. The only restriction is that the stator of the machine contains three balanced three-phase windings, with individual phases displaced by $120^{\circ}$ electrical along the circumference of the stator.

The application of interleaving strategy in the charging/V2G operations is also investigated. It is concluded that interleaving improves the grid current waveforms to a considerable extent in both single-phase and three-phase charging modes. However, the machine phase current distortion inevitably increases. This increase in distortion creates higher losses and affects the efficiency of the charger. However, since the grid current distortion is sufficiently low even without interleaving, it is recommended to operate without interleaving and consider the option of additional filters on the grid side of the topology or bespoke machine design which would increase the machine leakage inductance to limit the current harmonics.

\section{APPENDIX}

Controller: dSPACE DS1006 processor board. A DS2004 high speed $\mathrm{A} / \mathrm{D}$ board is used for the $\mathrm{A} / \mathrm{D}$ conversion of the measured machine's phase currents and grid voltages. A DS5101 digital waveform output board is used for the PWM signal generation, and the machine speed is read by a DS3002 incremental encoder interface board.

Nine-phase PM machine: The machine was obtained by rewinding the 36-slot stator of a 6-pole three-phase servo surface mounted permanent magnet machine with the data: $1.73 \mathrm{~kW}, 180 \mathrm{~V}$ (line-to-line), $150 \mathrm{~Hz}, 3000 \mathrm{rpm}, 5.5 \mathrm{Nm}$ (continuous). After re-winding, the rated per-phase data are $220 \mathrm{~V}, 1.47 \mathrm{~A}, 150 \mathrm{~Hz}$. Stator winding is triple-layer, full pitch, with $15^{\circ}$ degrees phase shift between first phases of the threephase windings.

\section{ACKNOWLEDGMENT}

This work was supported by the Engineering and Physical Sciences Research Council (EPSRC) National Centre for Power Electronics under grant reference EP/K035304/1 ("Addressing the range anxiety problem: A dual function integrated drive train/charger for future EVs").

\section{REFERENCES}

[1] J. de Santiago, H. Bernhoff, B. Ekergard, S. Eriksson, S. Ferhatovic, R. Waters, and M. Leijon, "Electrical motor drivelines in commercial allelectric vehicles: A Review," IEEE Trans. on Vehicular Technology, vol. 61, no. 2, pp. 475-484, 2012.

[2] E. Levi, "Multiphase electric machines for variable-speed applications," IEEE Trans. on Industrial Electronics, vol. 55, no. 5, pp. 1893-1909, 2008.

[3] I. Subotic, N. Bodo, and E. Levi, "Single-phase on-board integrated battery chargers for EVs based on multiphase machines," IEEE Trans. on Power Electronics, vol. 31, no. 9, pp. 6511-6523, 2016.

[4] I. Subotic, N. Bodo, E. Levi, and M. Jones, "Onboard integrated battery charger for EVs using an asymmetrical nine-phase machine," IEEE Trans. on Industrial Electronics, vol. 62, no. 5, pp. 3285-3295, 2015.

[5] I. Subotic and E. Levi, "A review of single-phase on-board integrated charging topologies for electric vehicles," in Proc. IEEE Workshop on Electrical Machines Design, Control and Diagnosis WEMDCD, Torino, Italy, pp. 136-145, 2015.

[6] S. Haghbin, S. Lundmark, M. Alakula, and O. Carlson, "Grid-connected integrated battery chargers in vehicle applications: Review and new solution," IEEE Trans. on Industrial Electronics, vol. 60, no. 2, pp. 459473, 2013.

[7] F. Lacressonniere and B. Cassoret, "Converter used as a battery charger and a motor speed controller in an industrial truck," in Proc. European Power Electronics and Applications Conf. EPE, Dresden, Germany, pp. $1-7,2005$.

[8] S. Haghbin, S. Lundmark, M. Alakula, and O. Carlson, "An isolated high-power integrated charger in electrified-vehicle applications," IEEE Trans. on Vehicular Technology, vol. 60, no. 9, pp. 4115-4126, 2011.

[9] X. Lu, K. L. V. Iyer, K. Mukherjee, and N. C. Kar, "Investigation of integrated charging and discharging incorporating interior permanent magnet machine with damper bars for electric vehicles," IEEE Trans. on Energy Conversion, vol. 31, no. 1, pp. 260-269, 2016.

[10] L. De Sousa, B. Silvestre, and B. Bouchez, "A combined multiphase electric drive and fast battery charger for electric vehicles," in Proc. IEEE Vehicle Power and Propulsion Conference VPPC, Lille, France, pp. 1-6, 2010.

[11] K. T. Chau, C. C. Chan, and C. Liu, "Overview of permanent-magnet brushless drives for electric and hybrid electric vehicles," IEEE Trans. on Industrial Electronics, vol. 55, no. 6, pp. 2246-2257, 2008.

[12] I. Subotic, M. Jones, and E. Levi, "A fast on-board integrated battery charger for four-motor EVs", in Proc. Int. Conf. on Electrical Machines ICEM, Berlin, Germany, pp. 2060-2066, 2014.

[13] D. Hadiouche, H. Razik, and A. Rezzoug, "On the modeling and design of dual-stator windings to minimize circulating harmonic currents for VSI fed AC machines," IEEE Trans. on Industry Applications, vol. 40, no. 2, pp. 506-515, 2004. 